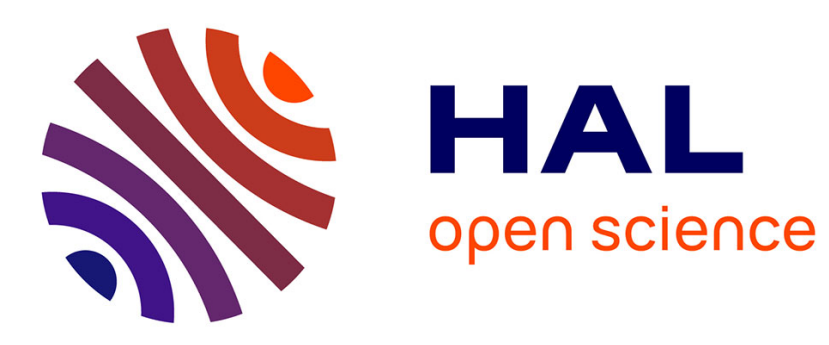

\title{
Proton conduction study of a new selenate-based hybrid compound
}

Dhouha Abid, Ikram Dhouib, Philippe Guionneau, Stanislav Pechev, Iskandar

Chaabane, Nathalie Daro, Zakaria Elaoud

\section{- To cite this version:}

Dhouha Abid, Ikram Dhouib, Philippe Guionneau, Stanislav Pechev, Iskandar Chaabane, et al.. Proton conduction study of a new selenate-based hybrid compound. Journal of Alloys and Compounds, 2020, 824, pp.153826. 10.1016/j.jallcom.2020.153826 . hal-02639224

\section{HAL Id: hal-02639224 \\ https://hal.science/hal-02639224}

Submitted on 10 Sep 2020

HAL is a multi-disciplinary open access archive for the deposit and dissemination of scientific research documents, whether they are published or not. The documents may come from teaching and research institutions in France or abroad, or from public or private research centers.
L'archive ouverte pluridisciplinaire HAL, est destinée au dépôt et à la diffusion de documents scientifiques de niveau recherche, publiés ou non, émanant des établissements d'enseignement et de recherche français ou étrangers, des laboratoires publics ou privés. 


\title{
Proton conduction study of a new selenate-based hybrid compound
}

\author{
Dhouha Abid ${ }^{\text {a, * }}$, Ikram Dhouib a, Philippe Guionneau ${ }^{\text {b }}$, Stanislav Pechev ${ }^{\text {b }}$, \\ Iskandar Chaabane $^{c}$, Nathalie Daro ${ }^{b}$, Zakaria Elaoud ${ }^{\text {a }}$ \\ a Laboratory Physical-Chemistry of Solid State, University of Sfax, Faculty of Sciences of Sfax, Tunisia \\ ${ }^{\mathrm{b}}$ CNRS, Univ. Bordeaux, ICMCB, 87 Avenue of Dr A. Schweitzer, 33608, Pessac, Bordeaux, France \\ c Unité de Recherche de La Matière Condensée, Faculté des Sciences de Sfax, Université de Sfax, BP 1171, 3000, Sfax, Tunisia
}

\begin{abstract}
A B S T R A C T
Ongoing studies aimed at developing a novel proton conducting solids, resulted in the new organic inorganic compound $\left[\left(\mathrm{C}_{2} \mathrm{H}_{5}\right)_{4} \mathrm{~N}\right] \mathrm{HSeO}_{4}\left(\mathrm{H}_{2} \mathrm{SeO}_{4}\right)_{2}$. The crystals were prepared by slow evaporation technique at room temperature. Crystal structure, thermal and electrical measurements were provided to characterize this compound. Single crystal X ray study showed that the new phase crystallizes belongs to the Cc space group of the monoclinic system with lattice parameters: $a=19.705$ (1) $\AA$; $b=7.5420$ (3) $\AA ; c=19.199$ (1) $\AA, \beta=115^{\circ}$. The structure consists of infinite two dimensional inter linkers via strong hydrogen bonds $(\mathrm{O} \mathrm{H} \cdots \mathrm{O})$ giving birth to trimers. Two phase transition were disclosed by differential thermal analysis and confirmed by electrical measurements and dielectric measurements. The complex impedance of the compound was investigated in the temperature range $290373 \mathrm{~K}$ and in the frequency range $113.10^{3} \mathrm{KHz}$. Besides, an electrical equivalent circuit was proposed to explain the impedance results. Electric and dielectric analyses reveal the presence of a relaxation phenomenon and highlight the good protonic conduction of this material.

Protons migration can be ascribed to the reorientation of protons carriers through hydrogen bonds, and then it occurs by the Grotthuss mechanism.
\end{abstract}

\section{Introduction}

During the past decade, proton conducting compounds have garnered huge attention as candidate for electrolytes in batteries, fuel cells, and sensors [1-4]. Different classes of compounds gained increasing interest as proton conductors such as ceramic oxides, carbon nanotubes, and organic polymers. Particularly, organic inorganic hybrid materials have been recently considered as one of the best promising candidates in term of applications regarding protons conducting. Their high degree of crystallinity, the design [5], the structural diversities and the ability to combine physical properties derived from the co existence of organic and inorganic elements appear as key factors [6-10].

In fact, across the systematic research that aim to better un derstand these features, a significant number of organic inorganic materials based on selenate have been already reported:

\footnotetext{
* Corresponding author. Sfax Faculty of Science, Chemistry Department, Soukra Road km 3,5 - B.P. 1171, 3018, Sfax, Tunisia.

E-mail address: zakaria_elaoud@yahoo.com (D. Abid).
}

$\left[\mathrm{C}_{3} \mathrm{H}_{7} \mathrm{~N}_{6}^{+}\right]_{4}\left(\mathrm{SeO}_{4}^{2-}\right)_{2} \cdot 3 \mathrm{H}_{2} \mathrm{O} \quad[11], \quad\left[\mathrm{C}_{6} \mathrm{H}_{5} \mathrm{CH}_{2} \mathrm{C}_{5} \mathrm{H}_{4} \mathrm{NH}\right] . \mathrm{HSeO}_{4} \quad[12]$, $\mathrm{C}\left(\mathrm{NH}_{2}\right) \cdot 3 \mathrm{HSeO}_{4}[13-15],\left(\mathrm{NH}_{4}\right)_{4} \mathrm{H}_{2}\left(\mathrm{SeO}_{4}\right)_{3}[16,17]$, [ $\left.\mathrm{N}\left(\mathrm{C}_{2} \mathrm{H}_{5}\right)_{4}\right] \cdot \mathrm{HSeO}_{4}$ [18]. In these materials, protons migration is ensured through hydrogen bonds involving and the coordinating atom, which is oxygen. The more extensive and stronger the cluster is, the faster the migration will be. Thus, a stronger hydrogen bond reduces the $\mathrm{O} \cdots \mathrm{O}$ distance and facilitates the close approach intended for transfer. Generally, the distances of the $\mathrm{O} \cdots \mathrm{O}$ interactions full in the range of 2.4-3 A. Such phenomenon gives rise directly to the two plausible main processes of proton conduction transfer known as Grotthus and vehicle mechanisms [19,20].

In the present study, focus is laid on the XRD and physical properties of new hybrid compound tetraethylammonium mono hydrogenselenate bis selenic acid $\left[\left(\mathrm{C}_{2} \mathrm{H}_{5}\right)_{4} \mathrm{~N}\right] \cdot \mathrm{HSeO}_{4} \cdot\left(\mathrm{H}_{2} \mathrm{SeO}_{4}\right)_{2}$ (hereafter abbreviated TESe).

The ultimate aim of this work is to reveal the phase transition from differential thermal analysis, conductivity analysis through complex impedance spectroscopy and dielectric measurements and give more information about the relaxation phenomenon. Thus, this makes it feasible to point the proton transport and transfer phenomena pathway, thereby leading to understand the 
proton conduction mechanism.

\section{Experimental details}

\subsection{Synthesis}

\subsubsection{Materials}

Reagents and Solvents were commercially available from Sigma Aldrich and used without further purification: selenic acid $\mathrm{H}_{2} \mathrm{SeO}_{4}$ (purity 98\%; Sigma Aldrich) and tetraethylammonium hydroxide $\left[\left(\mathrm{CH}_{3} \mathrm{CH}_{2}\right)_{4} \mathrm{~N}\right] \mathrm{OH}$ (purity 98\%; Sigma Aldrich).

\subsubsection{Preparation of TESe}

Crystal of TESe with the formula $\left[\left(\mathrm{C}_{2} \mathrm{H}_{5}\right)_{4} \mathrm{~N}\right] \mathrm{HSeO}_{4}\left(\mathrm{H}_{2} \mathrm{SeO}_{4}\right)_{2}$ was prepared by slow evaporation technique, at room temperature, from an aqueous solution containing selenic acid and tetraethy lammonium hydroxide in the stochiometric ratio 3:1. This mixture was stirred well till it became clear. Over a period of several days, colorless parallelepipedic crystals with high quality suitable for $\mathrm{X}$ ray single crystal experiments were obtained. The reaction scheme is given in the following equation (Scheme 1):

$\left[\left(\mathrm{C}_{2} \mathrm{H}_{5}\right)_{4} \mathrm{~N}\right]^{+} . \mathrm{OH}^{-}+3 \mathrm{H}_{2} \mathrm{SeO}_{4}\left[\left(\mathrm{C}_{2} \mathrm{H}_{5}\right)_{4} \mathrm{~N}\right]^{+} . \mathrm{HSeO}_{4}^{2-} .\left(\mathrm{H}_{2} \mathrm{SeO}_{4}\right)_{2}+$ $\mathrm{H}_{2} \mathrm{O}$

The density of the synthesized compound was measured at room temperature by pycnometry by flotation in carbon tetra chloride $\left(\mathrm{CCl}_{4}\right)$. The mean value of the measured density, $D_{m} \quad 1.709$, is in good accordance with that obtained from the crystal structure determination (see below).

\section{2. $X$ ray data collection}

In order to define the crystal structure, $\mathrm{X}$ ray diffraction in tensity data were collected within the limits of $2,1^{\circ} \leq \theta \leq 27,1^{\circ}$ at room temperature and then investigated using Bruker Kappa APEX II diffractometer using Mo $\mathrm{K} \alpha$ radiation source.

5609 reflections were recorded and among them 5472 checked the condition of intensity $\mathrm{I} \geq 3 \sigma$. Then, the structure of the title compound was solved within the WINGX software [21] in the monoclinic system with the non centro symmetric space group Cc. Heavy atoms such us selenic were fixed with Patterson methods using the SHELXS 86 program [22]. SHELXL 79 program [23] was used to facilitate the identification of carbon, oxygen and nitrogen atoms. The final cycle of refinement led to reliability factors $\mathrm{R}_{1} \quad 0.071$ and $\mathrm{wR}_{2} \quad 0.2187$. Furthermore, the drawings of the structure was made using Diamond [24].

Crystallographic and structure refinement details for the title compound are depicted in Table 1 . Atomic coordinates, $\mathrm{U}_{\mathrm{eq}} / \mathrm{U}_{\mathrm{iso}}$, inter atomic distances and angles are listed in Table S1 and Table S2.

\subsection{Thermal analysis}

Thermogravimetric analysis (TGA) and differential thermal analysis (DTA) measurements for TESe were performed by heating $3.809 \mathrm{mg}$ of powdered sample from $293 \mathrm{~K}$ to $523 \mathrm{~K}$. The TGA analysis was conducted in air at a heating rate of $10 \mathrm{~K} \mathrm{~min}^{-1}$.

\subsection{Electrical measurements}

The electrical studies were carried out in frequency ranges be tween 1 and $13.10^{3} \mathrm{KHz}$ by means of two silver electrode configu rations. In fact, the polycrystalline sample was pressed into $1.1 \mathrm{~mm}$ thick pellets with $8 \mathrm{~mm}$ diameter. These measurements were recorded in the temperature range from 290 to $373 \mathrm{~K}$ using a HEWLETT PACKARD 4192 ALF component analyzer.

\section{Results and discussion}

\subsection{Structure description}

The TESe hybrid compound crystallizes in the monoclinic crystal system with the Cc space group and lattice parameters: a 19.705

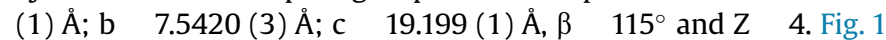
illustrate the perspective view of the sample in a three dimensional framework which reveals the organic and inorganic groups archi tecture. The unit formula is constituted of one independent $\left[\left(\mathrm{C}_{2} \mathrm{H}_{5}\right)\right.$ $\mathrm{N}]+$ cation, one $\left[\mathrm{HSeO}_{4}\right]^{-}$and two molecules of selenic acid $\mathrm{H}_{2} \mathrm{SeO}_{4}$ (Fig. 2). The projection of the atomic arrangement of Fig. 3 shows a projection of the structure along the $b$ axis. This latter illustrates a layered arrangement perpendicular to $a$ axis. The planes of the tetrahedron $\left[\mathrm{HSeO}_{4}\right]$ and $\mathrm{H}_{2} \mathrm{SeO}_{4}$ alternate with planes of organic groups.

The $\left[\left(\mathrm{C}_{2} \mathrm{H}_{5}\right) \mathrm{N}\right]+$ cation processes a tetrahedral geometry in the form of a broken cross. The $\mathrm{N}-\mathrm{C}$ and $\mathrm{C}-\mathrm{C}$ distances vary from 1.534 (19) to 1.64 (2) $\AA$ and from 1.566 (13) to 1.668 (15) respectively. The $\mathrm{C}-\mathrm{N}-\mathrm{C}$ angle ranges between $95.5^{\circ}(10)$ and $118.4^{\circ}(12)$. The mid planes of this unit are located at $x \quad 0$ and $x \quad 1 / 2$. These average values are comparable to the previously reported date ones for other similar hybrid compound [18,25].

On the other hand, the structure consists of strong two dimensional character based on sheets of $\mathrm{HSeO}_{4}^{-}$and $\mathrm{H}_{2} \mathrm{SeO}_{4}$ tetrahedra giving rise to an infinite $2 \mathrm{D}$ chains built up through $\left[\left(\mathrm{HSeO}_{4}\right)\left(\mathrm{H}_{2} \mathrm{SeO}_{4}\right)\right]_{\mathrm{n}}^{\mathrm{n}-}$ layers perpendicular to the $a$ axis. The mid planes of these layers are located at $x \quad 1 / 4$ and $x \quad 3 / 4$ (Fig. 4). Within these inorganic groups, the $\mathrm{Se}-\mathrm{O}$ distances in the $[\mathrm{HSe}(1)$ $\mathrm{O}_{4}$ ] anions vary from 1.776 (1) Å to 1.824 (2) Å.

In contrast, the $\mathrm{Se}-\mathrm{O}$ distances in the $\mathrm{H}_{2} \mathrm{Se}(2) \mathrm{O} 4$ and $\mathrm{H}_{2} \mathrm{Se}(3) \mathrm{O}_{4}$ are included between 1.688 (2) and 1.784 (1) respectively (Table 2). In fact, the longest Se-O distance [d Se-O] 1.824 (2) Å] is ascribed to the presence of an acidic hydrogen on the atom of the $\mathrm{SeO}_{4}$ tetrahedron. The $\mathrm{O}-\mathrm{Se}-\mathrm{O}$ angles are in the range from 104.7 $(6)^{\circ}$ to $115.8(6)^{\circ}$ in $\mathrm{HSe}(1) \mathrm{O}_{4}^{-}$anions and $101.7(6)^{\circ} 115.7(3)^{\circ}$ and $102.4(6)^{\circ} 114.7(7)^{\circ}$ in $\mathrm{H}_{2} \mathrm{Se}(2) \mathrm{O}_{4}$ and $\mathrm{H}_{2} \mathrm{Se}(3) \mathrm{O}_{4}$, respectively. These values clearly justify the distortion from the ideal tetrahedral geometry. The calculated mean values of the distortion indices are listed in Table 3. For the two $\mathrm{HSe}(1)_{4}^{-}$and $\mathrm{H}_{2} \mathrm{Se}(2) \mathrm{O}_{4}$ tetrahedral, a strong distortion of the $\mathrm{Se}-\mathrm{O}$ distances from those of $\mathrm{O}-\mathrm{O}$. These values confirm that the molecule $\mathrm{H}_{2} \mathrm{Se}$ (3) $\mathrm{O}_{4}$ is a slightly deformed tetrahedron. Bond distances and angles are comparable to those reported in [N $\left.\left(\mathrm{CH}_{3}\right)_{4}\right] \cdot \mathrm{HSeO}_{4}$ [26], $\left(\mathrm{C}_{3} \mathrm{H}_{7} \mathrm{~N}_{6}^{+}\right)_{4}\left(\mathrm{SeO}_{4}^{2-}\right)_{2} \cdot 3 \mathrm{H}_{2} \mathrm{O}$ [11] and $\mathrm{C}_{6} \mathrm{H}_{5} \mathrm{CH}_{2} \mathrm{C}_{5} \mathrm{H}_{4} \mathrm{NH}^{+}$. $\mathrm{HSeO}_{4}^{-}$[12], $\left(\mathrm{C}_{6} \mathrm{H}_{14} \mathrm{~N}_{2}\right)\left[\mathrm{MII}\left(\mathrm{H}_{2} \mathrm{O}\right)_{6}\right]\left(\mathrm{SeO}_{4}\right)_{2}$ [27].

The structure packing is stabilized through intermolecular hydrogen bonding interactions occurring between the inorganic moieties, giving rise to layers perpendicular to the a axis. Indeed, the $\mathrm{O}-\mathrm{H}$. . . O bonds range from 2.480 (16) to 2.784 (17) $\AA$. These interactions play a major role on the cohesion of the crystal

$$
\left[\left(\mathrm{C}_{2} \mathrm{H}_{5}\right)_{4} \mathrm{~N}\right]^{+} . \mathrm{OH}^{-}+3 \mathrm{H}_{2} \mathrm{SeO}_{4} \longrightarrow\left[\left(\mathrm{C}_{2} \mathrm{H}_{5}\right)_{4} \mathrm{~N}\right]^{+} . \mathrm{HSeO}_{4}{ }^{2-} .\left(\mathrm{H}_{2} \mathrm{SeO}_{4}\right)_{2}+\mathrm{H}_{2} \mathrm{O}
$$


Table 1

Crystallographic and structure refinement details for the title compound for TESe.

\begin{tabular}{|c|c|}
\hline Formula & {$\left[\left(\mathrm{C}_{2} \mathrm{H}_{5}\right)_{4} \mathrm{~N}\right] \mathrm{HSeO}_{4}\left(\mathrm{H}_{2} \mathrm{SeO}_{4}\right)_{2}$} \\
\hline Color/Shape & Colorless/Parallelipipedic \\
\hline $\operatorname{Mr}\left(\mathrm{g} \mathrm{mol}^{1}\right)$ & 564.17 \\
\hline Crystal system & Monoclinic \\
\hline Space group & $\mathrm{Cc}$ \\
\hline Density & 1.717 \\
\hline Crystal size (mm) & $0.40 \times 0.20 \times 0.10$ \\
\hline Unit-cell volume $\left(\mathrm{A}^{\circ 3}\right)$ & $2181.9(2)$ \\
\hline Temperature $(\mathrm{K})$ & $293(2)$ \\
\hline Diffractometer & Kappa CCD \\
\hline$a, b, c(\AA)$ & 19.705(1), 7.542(3), 16.199(1) \\
\hline$\alpha, \beta, \gamma\left({ }^{\circ}\right)$ & $90,115,90$ \\
\hline $\mathrm{Z}$ & 4 \\
\hline Radiation type & Mo $K_{\alpha}$ \\
\hline$\theta$ range for data collection $\left({ }^{\circ}\right)$ & $2.1 \leq \theta \leq 27.1$ \\
\hline No. of measured, independent and observed $[I>2 \sigma(I)]$ reflections & $5066,4383,3366$ \\
\hline Range of $\mathrm{h}, \mathrm{k}, \mathrm{l}$ & $-25 / 25 .-9 / 1 .-19 / 19$ \\
\hline $\mathrm{F}(000)$ & 1112 \\
\hline Rint & 0.029 \\
\hline$(\sin \theta / \lambda) \max \left(\AA^{1}\right)$ & 0.650 \\
\hline$R\left[F^{2}>2 \sigma\left(F^{2}\right)\right], w R\left(F^{2}\right), S$ & $0.071,0.217,1.03$ \\
\hline$\Delta \rho \max , \Delta \rho \min \left(\mathrm{e}^{3}{ }^{3}\right)$ & $1.45,-2.40$ \\
\hline $\mathrm{w}$ & $1 /\left[\sigma^{2}\left(F o^{2}\right)+(0.1662 P)^{2}+2.0887 P\right]$ where $P \quad\left(F_{o}^{2}+2 F_{\mathrm{c}}^{2}\right) / 3$ \\
\hline
\end{tabular}

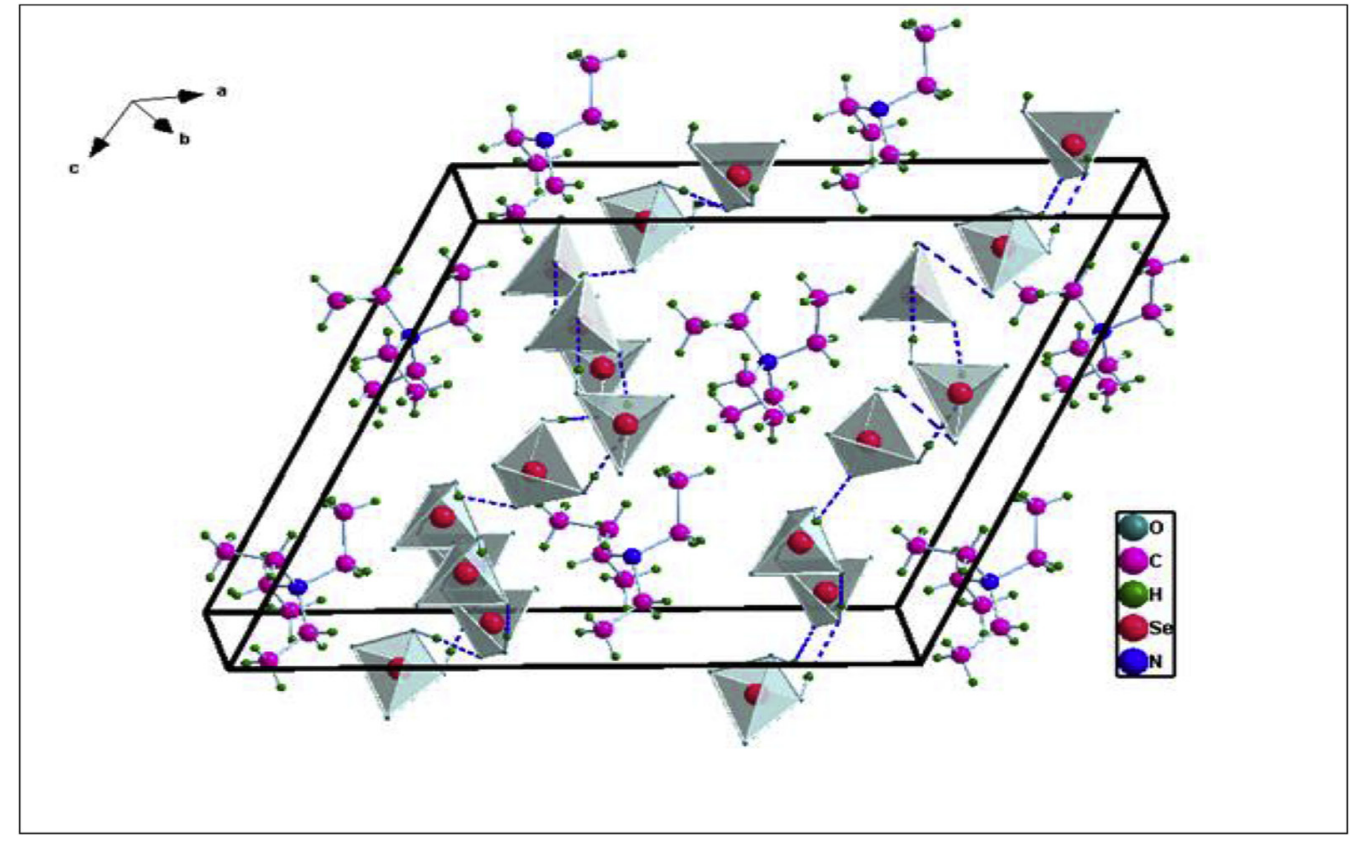

Fig. 1. Perspective view of TESe in a tree-dimensional framework.

structure and the construction of infinite bi dimensional frame works. Distances and angles describing hydrogen bonds are sum marized in Table 4.

\subsection{Thermal analysis}

In order to obtain information about the thermal decomposition of the synthesized compound, thermogravimetric measurements (TGA) and differential thermal analysis (DTA) were carried out in the temperature range from $293 \mathrm{k}$ to $523 \mathrm{~K}$. The results are reported in Figs. 5 and 6.

The TGA curve of the thermal decomposition reveals that the sample is devoid of water molecules since no mass loss was detected before the decomposition at $420 \mathrm{~K}$. The DTA curve shows three peaks: the first endothermic peak reaches $335 \mathrm{~K}$, the second transition at $350 \mathrm{~K}$ may be attributed to order disorder phase transition and the last exothermic peak observed at $393 \mathrm{~K}$ corre sponds to the decomposition of the material. These results suggest interesting electrical properties.

\subsection{Electrical properties}

\subsubsection{Impedance analysis and equivalent circuit}

The variation of the Nyquist plot ( Z" versus Z') of the TESe obtained from $223 \mathrm{~K}$ to $353 \mathrm{~K}$ is represented in Fig. 7. These dia grams exhibit some dispersion instead being a semi circle centered on the real axis, which indicates a Cole Cole empirical behavior [28]. The value of the parameter which characterizes the deviation 


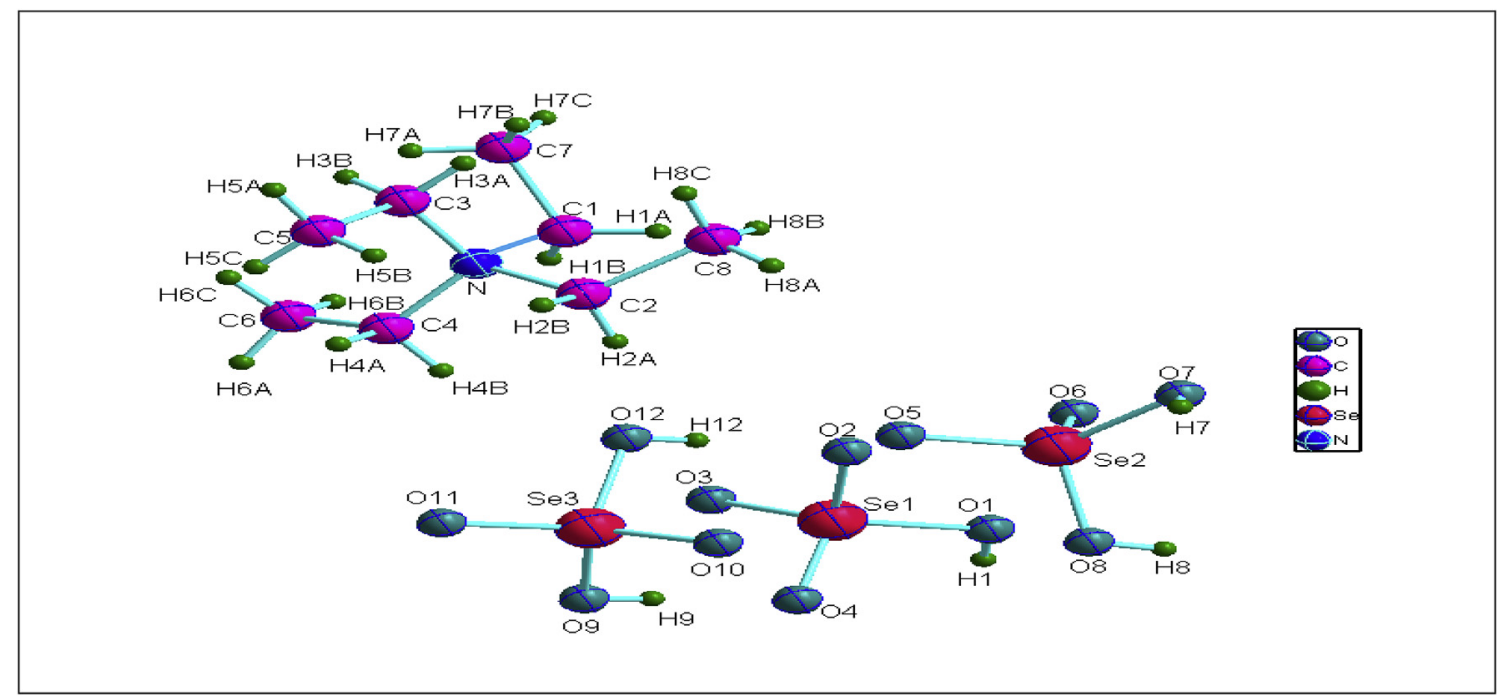

Fig. 2. Asymmetric unit of the TESe cristal.

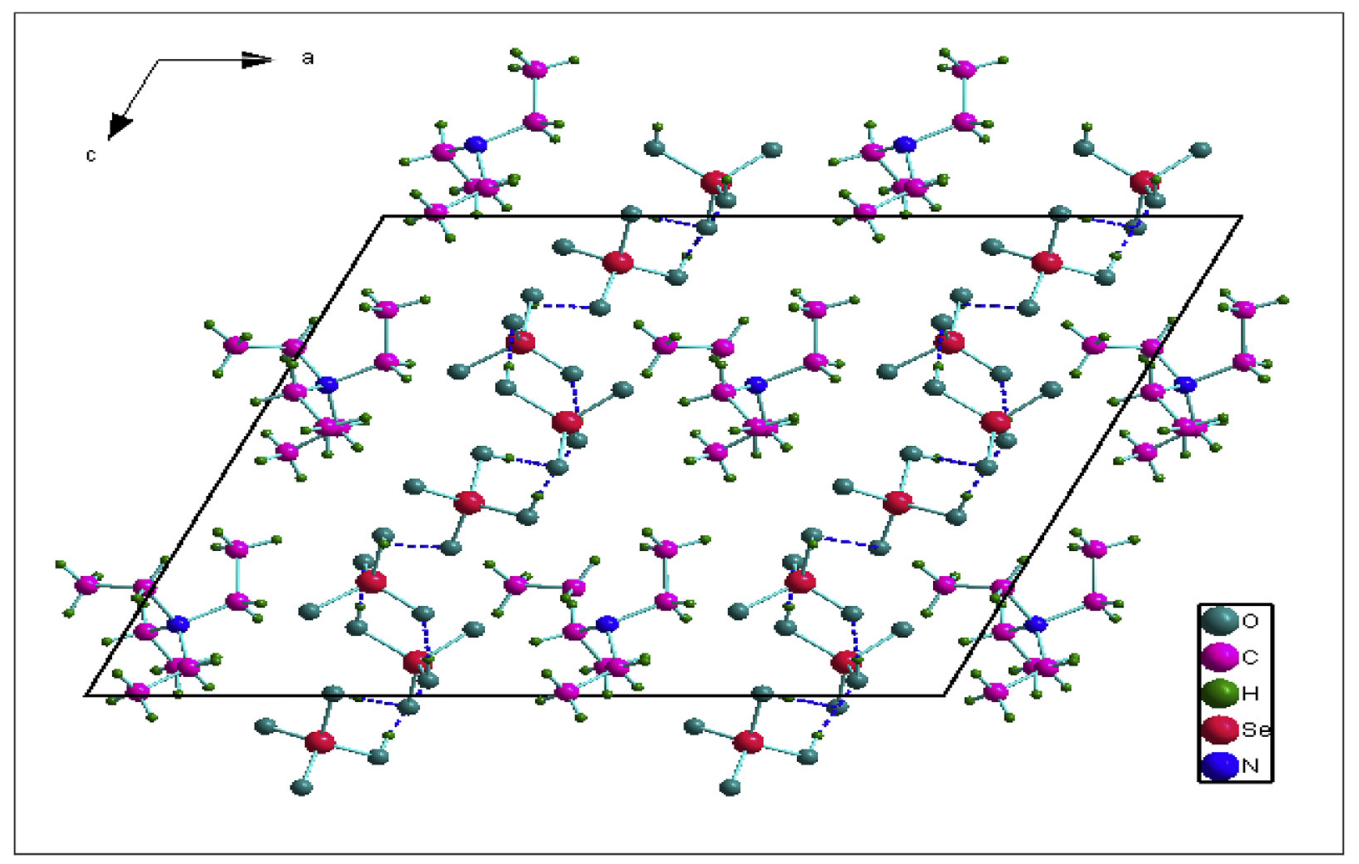

Fig. 3. Atomic arrangement of TESe along the b axis.

from the Debye law is of the order of 0.19. It is observed that temperature is directly proportional to the semi circles radius. Therefore, the increase of the temperature is followed by a decrease of the radius of semi circles and then a decrease in resistance. These observations are an indication of the existence of an activated conduction mechanism [28].

The series of Nyquist representations were modeled by means of $Z$ view software, fitted to an equivalent circuit composed of two elements connected in parallel: resistance $\mathrm{R}$ and fractal capacity CPE. In this case, the impedance of the fractal capacitance is. $Z_{(C P E)} \quad \frac{1}{\mathrm{Q}^{(\mathrm{i} \omega)^{\alpha}}}$ Where, $\mathrm{Q}$ represents the value of capacitance and $\alpha$ indicates the fractal exponent. $\left(Z^{\prime}\right)$ and $\left(Z^{\prime \prime}\right)$ were calculated from the following expressions:

$$
\begin{aligned}
& Z^{\prime} \frac{R^{2} \mathrm{~A}_{0} \omega^{\alpha} \cos \left(\frac{\propto \pi}{2}\right)+R \infty}{\left(1+\mathrm{RA}_{0} \omega^{\alpha} \cos ^{\prime}\left(\frac{\propto \pi}{2}\right)\right)^{2}+\left(\mathrm{RA}_{0}(\omega)^{\alpha} \sin \left(\frac{\propto \pi}{2}\right)\right)^{2}} \\
& Z^{\prime \prime} \frac{R^{2} A 0 \omega^{\alpha} \sin \left(\frac{\propto \pi}{2}\right) \infty}{\left(1+\mathrm{RA}_{0} \omega^{\alpha} \cos ^{\prime}\left(\frac{\alpha \pi}{2}\right)\right)^{2}+\left(\mathrm{RA}_{0}(\omega)^{\alpha} \sin \left(\frac{\alpha \pi}{2}\right)\right)^{2}}
\end{aligned}
$$

The variation of the real part $\left(Z^{\prime}\right)$ according to the frequency at different temperatures is depicted in Fig. 8. It is observed that the amplitude of $Z^{\prime}$ is higher in low frequency region at lower tem peratures. Afterwards, $Z^{\prime}$ decreases progressively with increasing both temperature and frequency. This behavior stands for an 


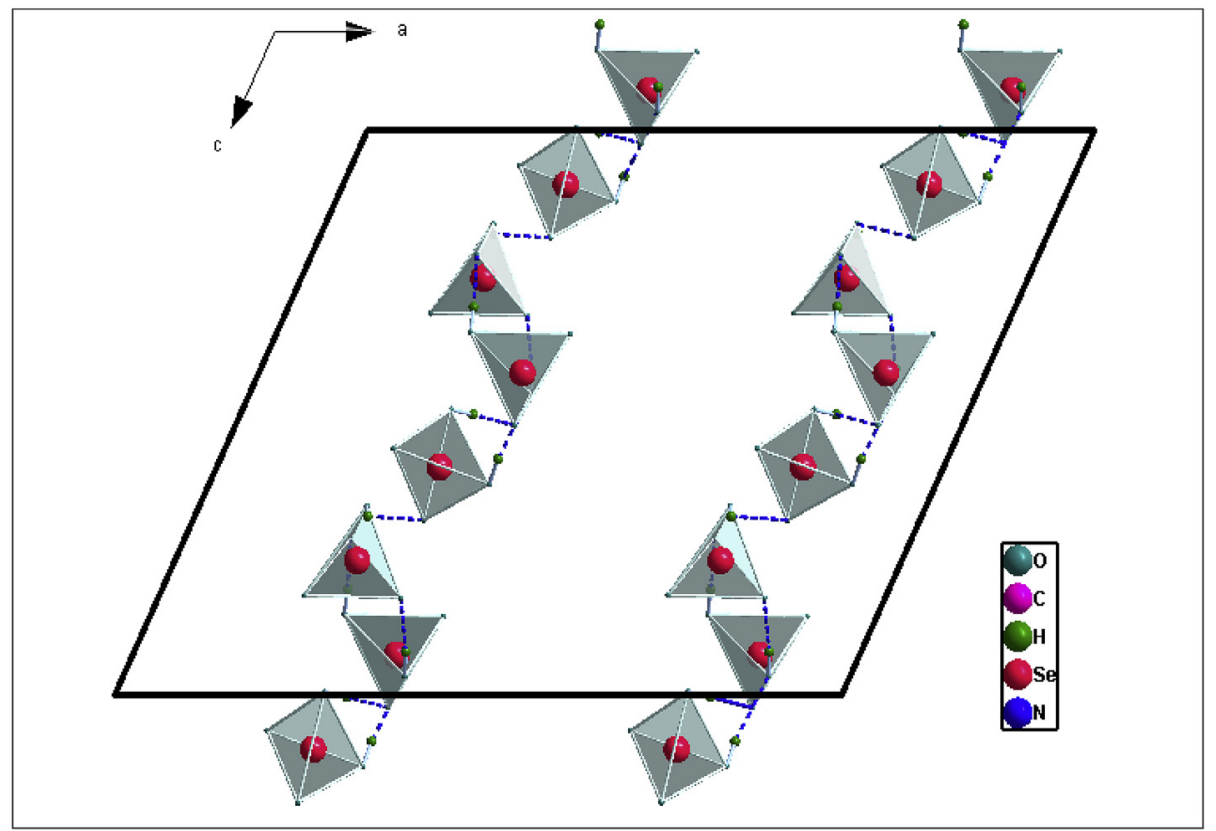

Fig. 4. Two dimensional sheet of the inorganic clusters where groups are linked through hydrogen bonds.

increase in the DC conductivity of the compound. All the curves consolidate at all temperatures and at higher frequencies, hence $Z^{\prime}$ becomes frequency independent. These observations confirm a possible release of the space charge, subsequently, the lowering of barrier properties [29].

The variation of the imaginary part Z" as a function of frequency at different temperatures is reported in Fig. 9. These curves show that $Z^{\prime \prime}$ moves to high frequency with increasing temperature until it reaches a maximum $\left(Z\right.$ ' $\left.{ }_{\text {max }}\right)$, then decreases progressively. In fact, the broadening of the peaks and the shift of $\left(Z^{\prime \prime} \max \right)$ to higher temperature confirm the existence of relaxation phenomena in the system as well as spreading of the relaxation time [30]. Further more, when frequency decreases, all curves merge. Such behavior indicates a possible release of the space charge mainly $\mathrm{H}^{+}$protons. At high frequency, the space charges have less time to relax, therefore the polarization of the space charge reduces with increasing frequency leading to the fusion.

Fig. 10 exhibits the variation of the real and the imaginary parts of the impedance $\left(Z^{\prime}\right.$ and $\left.Z^{\prime \prime}\right)$ according the frequency at $323 \mathrm{~K}$. It is clear that $Z^{\prime \prime}$ rises with increasing frequency while $Z^{\prime}$ decreases. This trend remains until $Z^{\prime \prime}$ reaches a maximum and intersects with $Z$ '. The maximum value corresponds to a particular frequency $f \mathrm{p}$ (relaxation frequency). Afterwards, Z' and Z" decline with increasing frequency until they coincide and reach zero.

Plots reported in Figs. 7-10 indicate a good agreement between experimental and simulated data denoting that the proposed equivalent circuit describes fairly well the electrical properties of the compound.

The dc conductivity was calculated from the following relationship:

$\sigma(\mathrm{dc}) \quad \frac{\mathrm{e}}{\mathrm{R} * \mathrm{~S}}$

where, $\mathrm{S}$ and e represent the area and the thickness of the pellets, respectively.

The variation of specific conductivity $\left(\operatorname{Ln}\left(\sigma_{\mathrm{dc}} \mathrm{T}\right)\right)$ versus $10^{3} / \mathrm{T}$ is given in Fig. 11. As it is observed, this curve indicates a rise in the conductivity of the material with an increase of the temperature. Such behavior indicates that the conduction in the compound is a thermally activated transport mechanism governed by the Arrhe nius law: $\sigma_{\mathrm{dc}} \mathrm{T} \quad \sigma_{0} \exp \left(\mathrm{E}_{\mathrm{a}} / \mathrm{kT}\right)$, where $\sigma_{0}$ is the pre exponential factor, Ea is the activation energy, $\mathrm{k}$ is the Boltzmann constant and $\mathrm{T}$ is the absolute temperature. Three regions were identified with changing of slope at $\mathrm{T}_{1} \quad 329$ and $\mathrm{T}_{2} \quad 338$.

An Arrhenius type law is shown and confirms the two phase transition already observed by DTA measurements at the same temperature. The phase I $\left(\mathrm{T}<\mathrm{T}_{1}\right)$ was characterized by an increasing conductivity $\left(\sigma_{\mathrm{dc}}>10^{-4} \Omega^{-1} \mathrm{~cm}^{-1}\right.$ ), which obeys the Arrhenius law: $\sigma \mathrm{T} \exp \left(\frac{-\mathrm{Ea}}{\mathrm{kT}}\right)$. At these temperatures, the slope of $\log (\sigma \mathrm{T})$ versus $10^{3} / \mathrm{T}$ gives an activation energy $\Delta \mathrm{E}_{1} \quad 0.91 \mathrm{eV}$. Afterwards, a decrease in the activation energy with increasing temperature from $\Delta \mathrm{E}_{1} \quad 0.91 \mathrm{eV}\left(\mathrm{T}<\mathrm{T}_{1}\right)$ to $\Delta \mathrm{E}_{2} \quad 0.43 \mathrm{eV}$ $(\mathrm{T} 1<\mathrm{T}<\mathrm{T} 2)$ was observed. This anomaly may be attributed to the disorder caused from the reorientation motion of inorganic groups. The phase II $\left(\mathrm{T}_{2}>\mathrm{T}\right)$ was characterized by an increasing conduc tivity when the temperature increases $\left(\sigma_{\mathrm{dc}}>10^{-3} \Omega^{-1} \mathrm{~cm}^{-1}\right)$. The Arrhenius law is obeyed and the activation energy increases to $\Delta \mathrm{E}_{2} \quad 0.61 \mathrm{eV}$. These high values of conductivity allow us to classify this salt among the super protonic conductors. The experimental values of the conductivity fitted according to the Arrhenius low are depicted in Table 5.

\subsubsection{Modulus analysis}

The formalism of the electric modulus: $\mathrm{M}^{*}$ is recognized as:

\section{$M^{*} \mathrm{j} \omega \mathrm{COZ}^{*}$}

$M^{*} M^{\prime}+\mathrm{iM}{ }^{\prime}$

where, $\mathrm{M}^{\prime}$ and $\mathrm{M}^{\prime \prime}$ are the real and imaginary parts of the complex modulus, obtained according to the following expression: 
Table 2

Selected interatomic distances and angles $\left(\AA{ }^{\circ}\right)$ for TESe sample.

\begin{tabular}{|c|c|c|c|}
\hline Se (1)-01 & $1.824(11)$ & $\mathrm{C} 4 \quad \mathrm{~N} \quad \mathrm{C} 1$ & $109.4(11)$ \\
\hline $\mathrm{Se}(1)-\mathrm{O} 2$ & $1.703(9)$ & C7 $\quad \mathrm{N} \quad \mathrm{C} 1$ & $95.5(10)$ \\
\hline $\mathrm{Se}(1)-03$ & $1.549(14)$ & $\mathrm{C} 2 \mathrm{~N} \quad \mathrm{C} 8$ & $118.4(12)$ \\
\hline Se (1)-O4 & $1.766(8)$ & C7 C1 H1A & 112.7 \\
\hline Se (2)-O5 & $1.719(10)$ & $\mathrm{N} \quad \mathrm{C} 1 \mathrm{H} 1 \mathrm{~A}$ & 112.7 \\
\hline Se (2)-O6 & $1.695(9)$ & C7 C1 H1B & 112.7 \\
\hline Se (2)-O7 & $1.730(13)$ & N C1 H1B & 112.7 \\
\hline Se (2)-08 & $1.784(11)$ & $\mathrm{H} 1 \mathrm{~A}-\mathrm{C} 1-\mathrm{H} 1 \mathrm{~B}$ & 110.1 \\
\hline Se (3)-09 & $1.723(13)$ & $\mathrm{N} \quad \mathrm{C} 2 \mathrm{H} 2 \mathrm{~A}$ & 107.7 \\
\hline $\mathrm{Se}(3)-010$ & $1.688(16)$ & C8 $\mathrm{C} 2 \mathrm{H} 2 \mathrm{~A}$ & 107.7 \\
\hline Se (3)-011 & $1.688(16)$ & $\mathrm{H} 2 \mathrm{~A}-\mathrm{C} 2-\mathrm{H} 2 \mathrm{~B}$ & 107.1 \\
\hline Se (3)-012 & $1.774(7)$ & $\mathrm{N}$ C2 $\mathrm{H} 2 \mathrm{~B}$ & 107.7 \\
\hline $\mathrm{C} 1 \mathrm{~N}$ & $1.64(2)$ & $\mathrm{N} C 3 \mathrm{H} 3 \mathrm{~A}$ & 109.5 \\
\hline $\mathrm{C} 2 \mathrm{~N}$ & $1.563(14)$ & C5 $\mathrm{C} 3 \mathrm{H} 3 \mathrm{~A}$ & 109.5 \\
\hline $\mathrm{C} 3 \mathrm{~N}$ & $1.488(14)$ & $\mathrm{N}$ C3 H3B & 109.5 \\
\hline $\mathrm{C} 4 \mathrm{~N}$ & 1.534 (19) & C5 C3 Н3B & 109.5 \\
\hline C1 C7 & 1.615 (17) & Н3А-С -Н3В & 108.1 \\
\hline $\mathrm{C} 2 \mathrm{C} 8$ & $1.668(15)$ & $\mathrm{C} 3 \mathrm{C} 5 \mathrm{H} 5 \mathrm{~A}$ & 109.5 \\
\hline C3 C5 & $1.566(13)$ & C3 C5 H5B & 109.5 \\
\hline C1 H1A & 0.9700 & H5A-C5-H5B & 109.5 \\
\hline C1 H1B & 0.9700 & C3 C5 H5C & 109.5 \\
\hline $\mathrm{C} 2 \mathrm{H} 2 \mathrm{~A}$ & 0.9700 & $\mathrm{H} 5 \mathrm{~A}-\mathrm{C} 5-\mathrm{H} 5 \mathrm{C}$ & 109.5 \\
\hline $\mathrm{C} 2 \mathrm{H} 2 \mathrm{~B}$ & 0.9700 & C2 C8 H8A & 109.5 \\
\hline C $3 \mathrm{H} 3 \mathrm{~A}$ & 0.9700 & C2 C8 H8B & 109.5 \\
\hline С 3 Н3В & 0.9700 & H8A-C8-H8B & 109.5 \\
\hline C5 H5A & 0.9700 & $\mathrm{C} 2 \mathrm{C} 8 \mathrm{H} 8 \mathrm{C}$ & 109.5 \\
\hline C5 H5B & 0.9600 & $\mathrm{H} 8 \mathrm{~A}-\mathrm{C} 8-\mathrm{H} 8 \mathrm{C}$ & 109.5 \\
\hline $\mathrm{C} 5 \mathrm{H} 5 \mathrm{C}$ & 0.9600 & H8B C8 H8C & 109.5 \\
\hline C8 H8A & 0.9600 & $\mathrm{~N} \quad \mathrm{C} 4 \mathrm{H} 4 \mathrm{~A}$ & 107.4 \\
\hline C8 H8B & 0.9600 & C6 C4 H4B & 107.4 \\
\hline $\mathrm{C} 2 \quad \mathrm{~N} \quad \mathrm{C} 1$ & $101.4(12)$ & $\mathrm{N} \quad \mathrm{C} 4 \mathrm{H} 4 \mathrm{~B}$ & 107.0 \\
\hline $\mathrm{C} 3 \mathrm{~N} \quad \mathrm{C} 5$ & $110.8(11)$ & $\mathrm{H} 4 \mathrm{~A}-\mathrm{C} 4-\mathrm{H} 4 \mathrm{~B}$ & 109.5 \\
\hline $\mathrm{C} 3 \mathrm{~N} \quad \mathrm{C} 2$ & $110.1(12)$ & $\mathrm{C} 4 \mathrm{C} 6 \mathrm{H} 6 \mathrm{~A}$ & 109.5 \\
\hline $\mathrm{C} 3 \mathrm{~N} \quad \mathrm{C} 4$ & $111.9(12)$ & C4 C6 H6B & 109.5 \\
\hline $\mathrm{C} 4 \mathrm{~N} \quad \mathrm{C} 2$ & $109.4(11)$ & H6A-C6-H6B & 109.5 \\
\hline C3 $\quad \mathrm{N} \quad \mathrm{C} 1$ & $110.7(12)$ & $\mathrm{C} 4 \mathrm{C} 6 \mathrm{H} 6 \mathrm{C}$ & 109.5 \\
\hline C1 C7 H7B & 109.5 & $\mathrm{C} 1 \mathrm{C} 7 \mathrm{H} 7 \mathrm{C}$ & 109.5 \\
\hline H7A-C7-H7B & 109.5 & H7A-C7-H7C & 109.5 \\
\hline H7B C7 H7C & 109.5 & O6 Se2 O5 & $112.8(5)$ \\
\hline O3 Se (1)-O1 & $106.6(6)$ & O5 $\mathrm{Se} 2 \mathrm{O}$ & $107.2(6)$ \\
\hline $\mathrm{O} 2 \mathrm{Se}(1)-04$ & $112.3(5)$ & O5 Se2 08 & $115.7(3)$ \\
\hline $\mathrm{O} 3 \mathrm{Se}(1)-\mathrm{O} 2$ & $115.8(6)$ & O6 Se2 O7 & $107.1(6)$ \\
\hline O4 Se (1)-01 & $109.4(5)$ & O6 Se2 08 & $101.7(6)$ \\
\hline $\mathrm{O} 3 \mathrm{Se}(1)-04$ & $104.7(6)$ & 010 Se3 011 & $114.7(7)$ \\
\hline O10 Se3 O9 & $109.3(7)$ & 010 Se3 012 & $102.4(6)$ \\
\hline O9 Se3 012 & $113.4(5)$ & 011 Se3 012 & $108.3(5)$ \\
\hline 011 Se3 o9 & $108.7(6)$ & $\mathrm{O} 2 \mathrm{Se}(1)-01$ & $107.8(5)$ \\
\hline
\end{tabular}

Table 3

Calculated mean values of the distortion indices.

\begin{tabular}{llll}
\hline & ID $(\mathrm{OSeO})$ & ID $(\mathrm{OSeO})$ & ID $(\mathrm{OOO})$ \\
\hline$\left[\mathrm{HSe}(1) \mathrm{O}_{4}\right]$ & 0.0127 & 0.0012 & 0.00008 \\
$\mathrm{H}_{2} \mathrm{Se}(2) \mathrm{O}_{4}$ & 0.028 & 0.0002 & 0.00006 \\
$\mathrm{H}_{2} \mathrm{Se}(3) \mathrm{O}_{4}$ & 0.0001 & 0.007 & 0.0083 \\
\hline
\end{tabular}

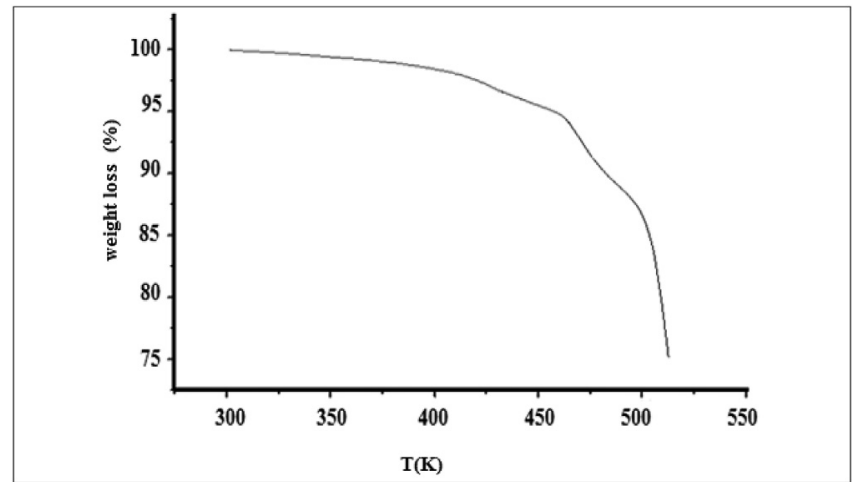

Fig. 5. Thermogravimetric analysis plot of TESe.

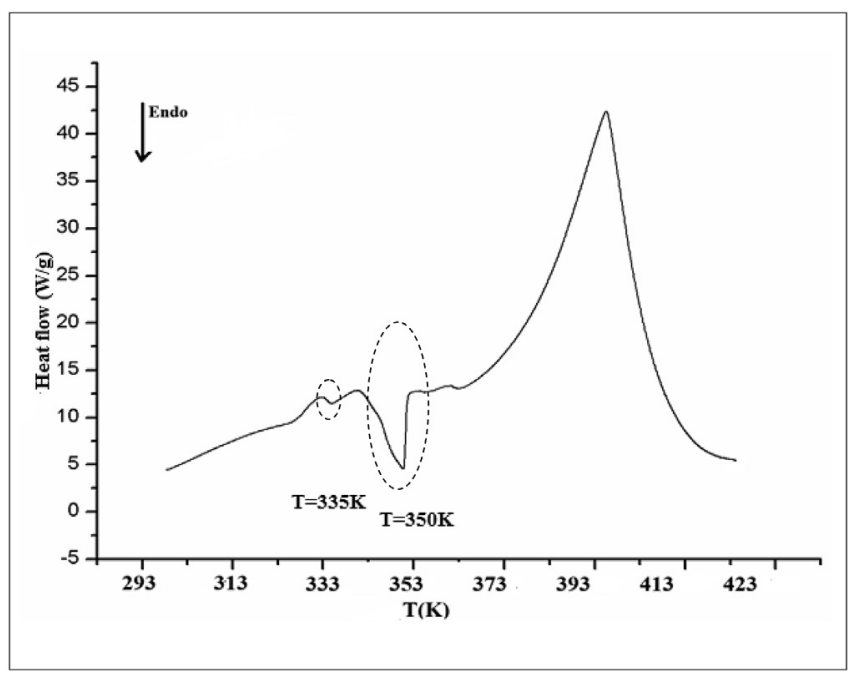

Fig. 6. DTA curves of $\left[\left(\mathrm{C}_{2} \mathrm{H}_{5}\right)_{4} \mathrm{~N}\right] \mathrm{HSeO}_{4}\left(\mathrm{H}_{2} \mathrm{SeO}_{4}\right)_{2}$.

\section{$M^{\prime} \omega \mathrm{COZ}^{\prime}$ \\ $M^{\prime \prime} \omega \mathrm{COZ}$,}

where, $C_{0}$ presents the vacuum capacitance of the cell.

This formalism has proved to be a forcefulparameter to obtain further information about the relaxation mechanism as well as charge transport processes in the system and optimize the con centration of the charge carriers, mainly $\mathrm{H}^{+}$protons.

In order to verify the contribution of these phenomena, we examined the variation of $\mathrm{M}^{\prime}$ versus ( $\log \mathrm{f}$ ) at several temperatures (Fig. 12). At all measured temperatures, curves display a low value of the real part $\mathrm{M}^{\prime}$ at low frequencies. Such observation can be related to a lack of force that governs the mobility of the charge carriers within the influence of the induced electric field. This

Table 4

Geometrical characteristics of hydrogen bonds $\left(\AA{ }^{\circ}\right)$.

\begin{tabular}{|c|c|c|c|c|}
\hline $\mathrm{D}-\mathrm{H} \ldots \mathrm{A}$ & $\mathrm{d}(\mathrm{D}-\mathrm{H})(\hat{A})$ & $\mathrm{d}(\mathrm{H} \ldots \mathrm{A})(\hat{A})$ & $\mathrm{d}(\mathrm{D} \ldots \mathrm{A})(\hat{A})$ & $\angle \mathrm{D}-\mathrm{H} \quad \mathrm{A}\left({ }^{\circ}\right)$ \\
\hline O1 H1 O5 (i) & 0.82 & 1.90 & $2.480(16)$ & 172 \\
\hline O8 H8 011 (ii) & 0.82 & 1.86 & $2.668(15)$ & 172 \\
\hline O7 H7 O9(iii) & 0.82 & 2.00 & $2.788(19)$ & 172 \\
\hline O9 H9 $\mathrm{O} 3$ & 0.82 & 1.97 & $2.784(17)$ & 170 \\
\hline O12 H12 O2 & 0.82 & 1.95 & $2.759(13)$ & 162 \\
\hline
\end{tabular}

Symmetry codes: (i) $x, y-1, z$; (ii) $x,-y+1, z-1 / 2$; (iii) $x,-y, z-1 / 2$. 


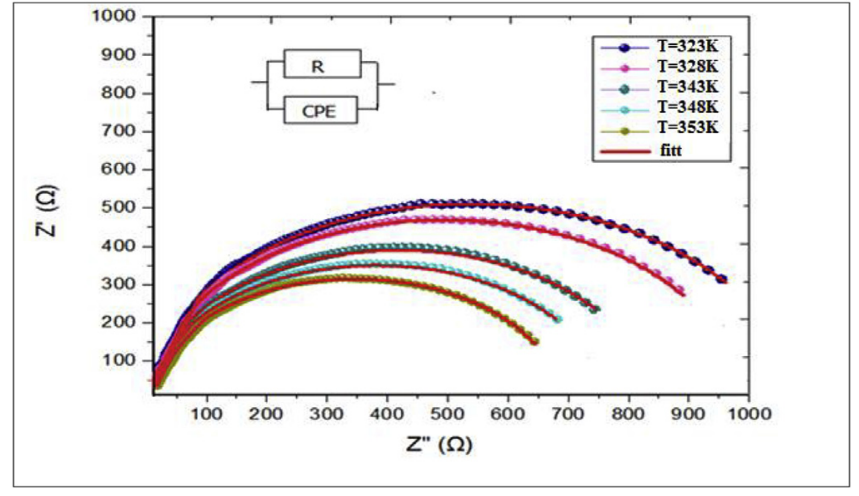

Fig. 7. Nyquist plot (-Z" versus $Z^{\prime}$ ) of TESe from $290 \mathrm{~K}$ to $373 \mathrm{~K}$.

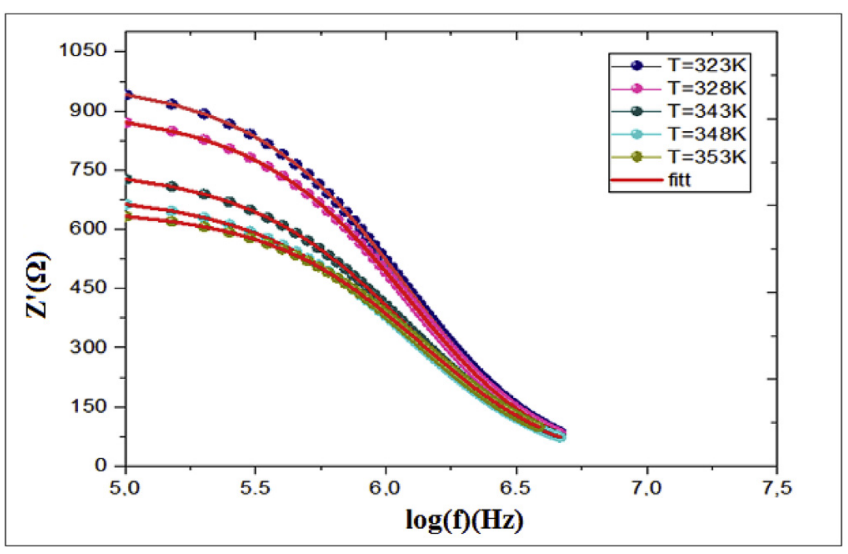

Fig. 8. Fluctuation of the real part $\left(Z^{\prime}\right)$ according to the frequency at different temperatures for TESe.

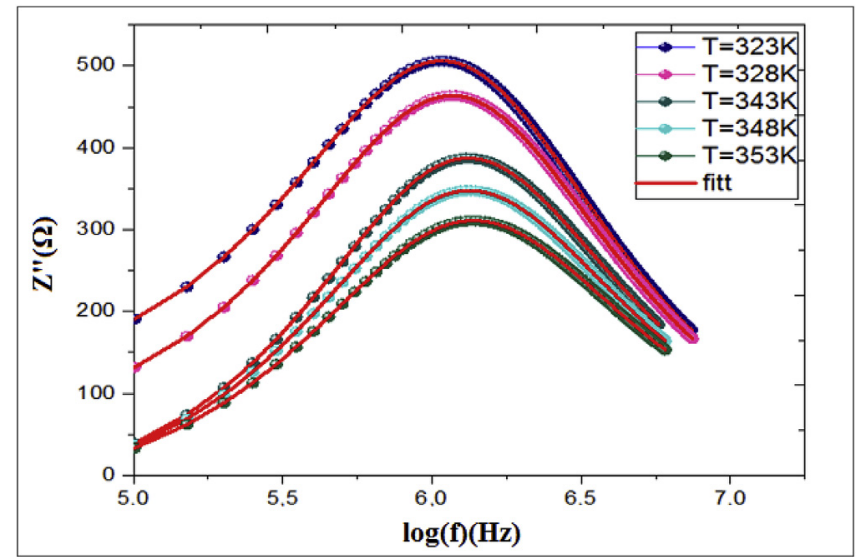

Fig. 9. Plot of the imaginary part $\left(Z^{\prime}\right)$ according to the frequency at different temperatures.

behavior promotes the long range mobility of $\mathrm{H}^{+}$protons. Furthermore, the rises of the value of M' until it reaches a constant value $\left(M^{\prime} \infty \frac{1}{\varepsilon^{\prime} \infty}\right)$ may be assigned to a conduction mechanism ascribed to the short range mobility of $\mathrm{H}^{+}$protons.

The 3D and 2D presentations of the imaginary part of modulus normalized (M"/M max) as a function of frequency at different temperatures is depicted in Fig. 13. In fact, these curves show a well defined asymmetric peak which shifts to higher Frequencies,

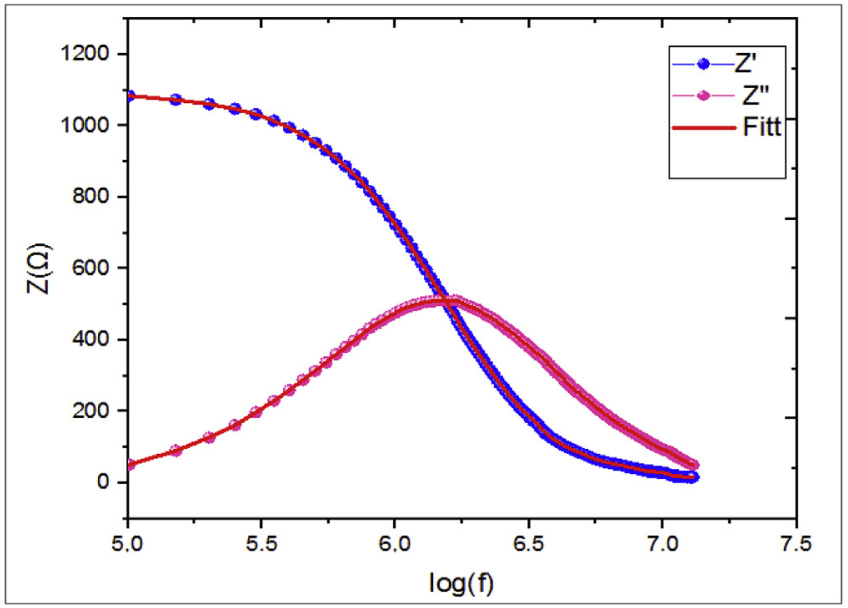

Fig. 10. Variation of the real and the imaginary parts of impedance $\left(Z^{\prime}\right.$ and $\left.Z^{\prime \prime}\right)$ according the frequency at $323 \mathrm{~K}$.

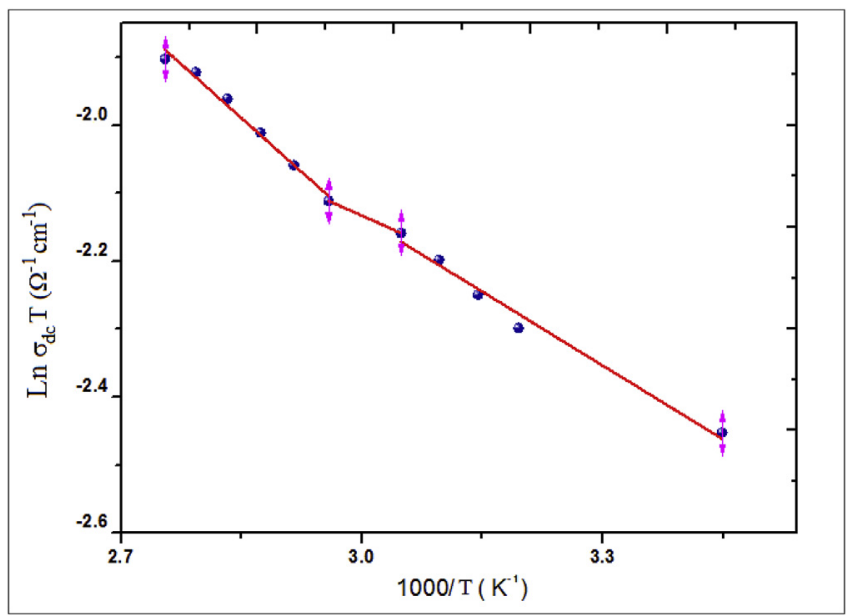

Fig. 11. Variation of specific conductivity $\left(\operatorname{Ln}\left(\sigma_{\mathrm{dc}} \mathrm{T}\right)\right)$ versus $10^{3} / \mathrm{T}$ for TESe compound.

Table 5

The experimental values of the conductivity for TESe sample.

\begin{tabular}{|c|c|c|}
\hline $\mathrm{T}(\mathrm{K})$ & $\sigma_{\mathrm{dc}}\left(10{ }^{4} \Omega{ }^{1} \mathrm{~cm}^{1}\right)$ & Ea (ev) \\
\hline 290 & 3.09 & \multirow{7}{*}{0.91} \\
\hline 308 & 4.12 & \\
\hline 313 & 4.57 & \\
\hline 318 & 7.79 & \\
\hline 323 & 6.51 & \\
\hline 328 & 6.54 & \\
\hline 338 & 6.95 & \\
\hline$T(K)$ & $\sigma_{\mathrm{dc}}\left(10^{3} \Omega^{1} \mathrm{~cm}^{1}\right)$ & $\mathrm{Ea}(\mathrm{ev})$ \\
\hline 343 & 1.13 & \multirow{5}{*}{0.61} \\
\hline 348 & 1.29 & \\
\hline 353 & 1.37 & \\
\hline 358 & 1.45 & \\
\hline 363 & 1.51 & \\
\hline
\end{tabular}

as the temperature increases. These peaks ( $\left.\mathrm{M}{ }^{\prime \prime} \max \right)$ can be associ ated to characteristic relaxation rate and exhibit asymmetric fre quency dependence. At low frequency region, the $\mathrm{H}^{+}$protons are mobile over long distances. At high frequencies, $\mathrm{H}^{+}$protons are confined to their potential wells, being mobile over short distances. However, the region of transition from a long distance to short 


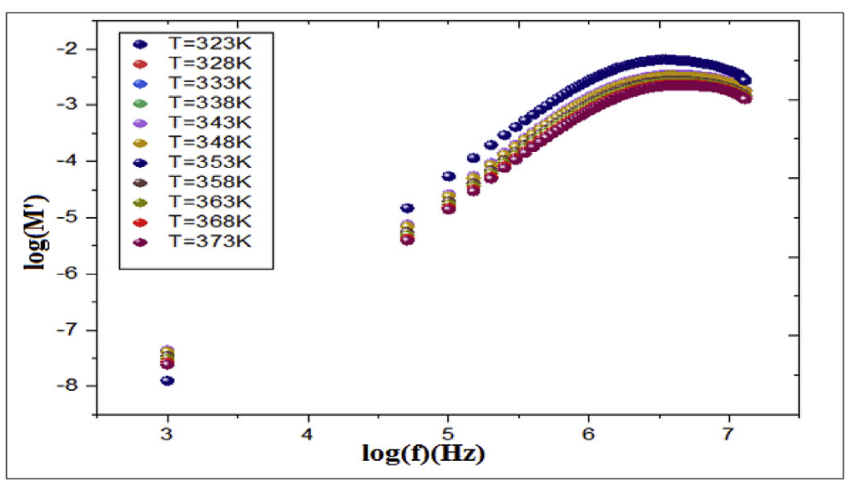

Fig. 12. Variation of $\mathrm{M}^{\prime}$ according to (log $\mathrm{f}$ ) at several temperatures.

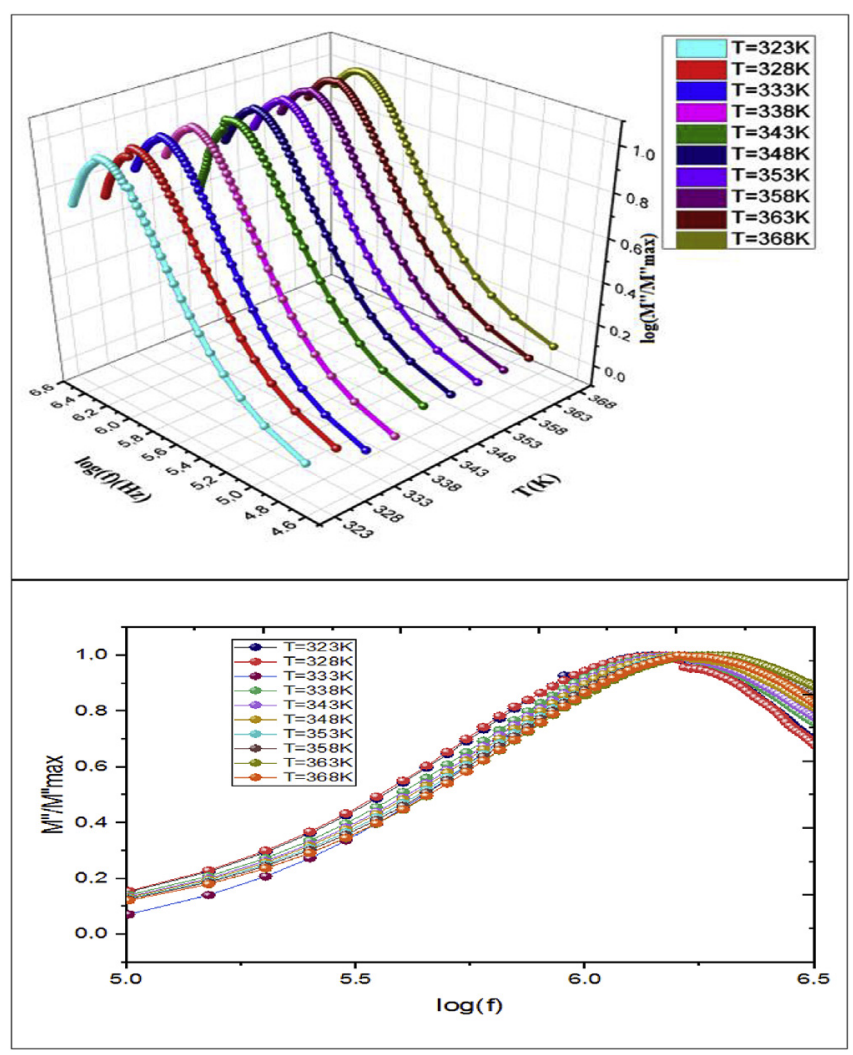

Fig. 13. Frequency dependence of the imaginary part of modulus normalized (M'/M $\max$ ) at various temperatures.

distance mobility is close to the asymmetric peak [31]. Moreover, it is revealed that the maximum of the asymmetric peak (M" $\max$ ) of modulus curves correspond to the bulk of relaxation frequency $f \mathrm{p}$ ( $f \mathrm{p} 2 \pi \tau_{\max }$ ). On the other hand, this frequency is defined by the relation: $\tau_{\max } \omega_{\max } 1$, where $\tau_{\max }$ presents the most probable proton relaxation time [32].

The electric relaxation process is well described, in general, by the KWW decay function (numerical Laplace transform of the Kohlrausch-Williams $s_{\beta}$ Watts) presented as.

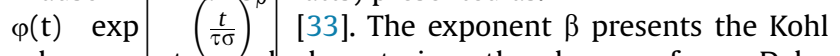
rausch parameter and characterizes the degree of non Debye behavior ( 1.14 decades). This parameter ranging between [0-1] is found to be 0.75 .

In Fig. 14, the variation of $\operatorname{Ln}\left(\sigma_{\mathrm{dc}} \mathrm{T}\right)$ and $\log (f \mathrm{p})$ with the inverse of the temperature. The conductivity $\operatorname{Ln}\left(\sigma_{\mathrm{dc}} \mathrm{T}\right)$ and the relaxation

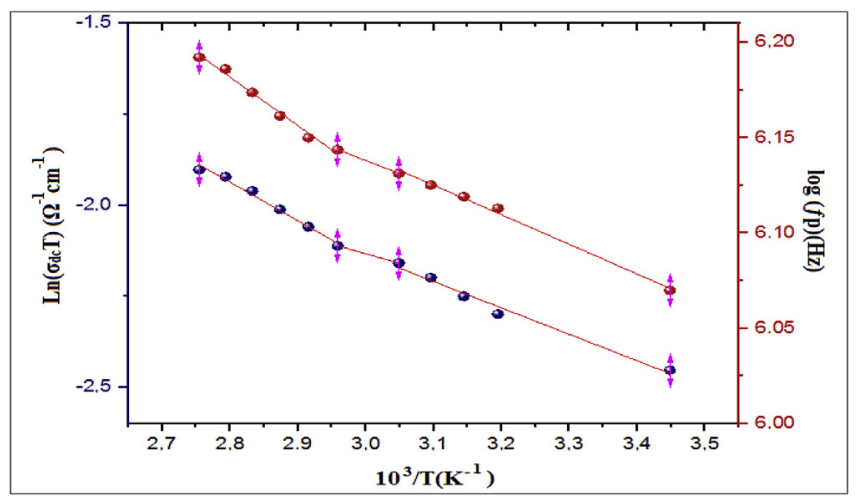

Fig. 14. Variation of $\operatorname{Ln}\left(\sigma_{\mathrm{dc}} \mathrm{T}\right)$ and $\log (f \mathrm{p})$ according to the inverse of temperature for TESe.

frequency $\log (f \mathrm{p})$ are depicted by two quasi parallel line segments and they present a discontinuity at 329 and $338 \mathrm{~K}$. These results confirm the two phase transitions observed in DTA analysis and conductivity measurements.

\subsubsection{Ac electrical conductivity}

The electric conductivity presents key approach in term of dis playing information about electrical dynamic including conduc tivity, capacitance and loss factor in the sample. It is also useful in identifying the nature of the conduction.

The Ac conductivity is derived from impedance complex data according to the following formula:

$\sigma_{\mathrm{ac}}\left(\frac{e}{s}\right)\left(\frac{Z^{\prime}}{Z^{\prime 2}+Z^{\prime \prime 2}}\right)$

The variation of the ac conductivity according to the frequency is shown in Fig. 15. It is noteworthy that, the ac conductivity is almost constant at low frequency. Then, it exhibits dispersion at high fre quency. Consequently, the rises in frequency ameliorate the jumping frequency of charge carriers, leading to a rise of the con duction process and then an increase of the conductivity. In addi tion, this feature denotes the presence of a thermally activated process generated from an increase pertaining to the energy of the charge carriers. At lower frequencies, the applied electric field compels the charge carriers to move over large distance [34]. Thus, the mean movements of the charge carriers are reduced with the increasing frequency.

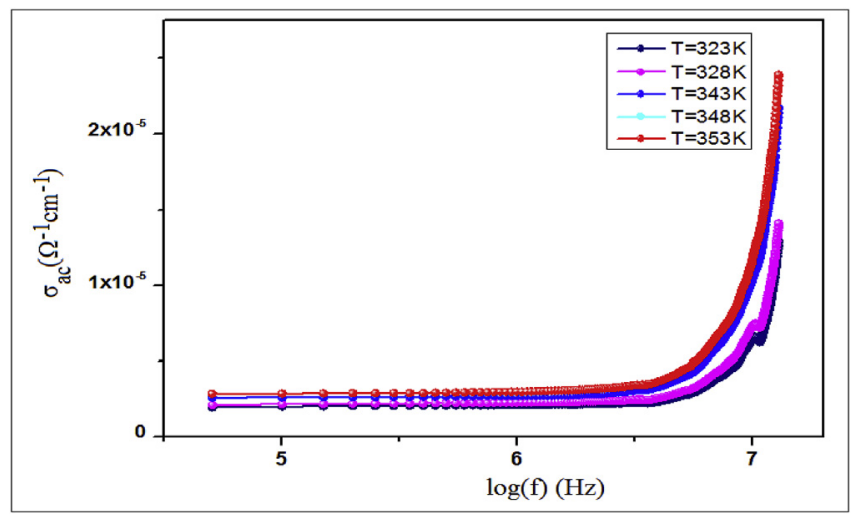

Fig. 15. Variation of the ac conductivity according to the frequency for different temperatures. 


\subsection{Dielectric studies}

Dielectric relaxation is an alternative approach to reveal reliable information about mechanisms of conduction, the origin of the dielectric losses, and to characterize phase transition detected in the ATD curve at $396 \mathrm{~K}$. The dielectric relaxation is described by a non Debye model which can be expressed as:

$\varepsilon^{*} \varepsilon^{\prime}+i \varepsilon^{\prime \prime}$

where $\varepsilon_{\infty}$ is the permittivity at high frequency value of $\varepsilon^{\prime}, \tau_{1}$ is the relaxation time, $\varepsilon_{S}$ presents the static permittivity, $\omega$ is the angular frequency and $\alpha$ is the tilting angle of the circular arc from the real axis in the complex permittivity plane [35].

Real and imaginary parts of the electric permittivity were calculated according to the following relations:

$$
\begin{aligned}
& \varepsilon^{\prime} \frac{Z^{\prime \prime}}{\omega C_{0}\left(Z^{2}+Z^{\prime \prime 2}\right)} \\
& \varepsilon^{\prime \prime} \frac{Z^{\prime}}{\omega C_{0}\left(Z^{\prime 2}+Z^{\prime \prime 2}\right)}
\end{aligned}
$$

Figs. 16 and 17 presents the temperature dependence of $\left(\varepsilon^{\prime}\right)$ and $\left(\varepsilon^{\prime \prime}\right)$ (real and imaginary parts) of the electric permittivity for TESe. It can be noted that, at low temperature, the fluctuation of $\varepsilon^{\prime}$ and $\varepsilon^{\prime \prime}$ with temperature is almost constant. This behavior can be explained by limited reorientation movements of the inorganic groups ( $\left[\mathrm{HSeO}_{4}\right]$ and $\mathrm{H}_{2} \mathrm{SeO}_{4}$ ) which are unable to orient them selves to the direction of the applied electric field. Hence, they acquire a feeble contribution to the polarization [36]. Afterwards, an asymmetric loss peak was detected at $333 \mathrm{~K}$, this anomaly is may be due to a disorder in the lattice generated from the reorientation motion of inorganic chains which reduces the Van Der Waals in teractions between the ions that leave to another unit cell let behind a vacancy [37,38]. This anomaly arises when the hopping frequency of localized charge carriers becomes approximately even to that of the applied electric field [39]. At high temperature, all curves of $\left(\varepsilon^{\prime}\right)$ and $\left(\varepsilon^{\prime \prime}\right)$ increase until they reach a large maximum approximately at $359 \mathrm{~K}$, featuring the phase transition, and then decrease at all measured frequencies. Over the phase transition, the units have enough thermal energy to adapt more easily to the change of the external electric field. This behavior can be elucidated by a weakness of the Van Der Waals interaction between ions as a result of the disorder and the inorganic groups reorientation motion.

The ratio of the loss factor $\varepsilon^{\prime \prime}$ r divided by the actual permittivity $\varepsilon_{\mathrm{r}}^{\prime}$ is defined as the tangent losses $(\tan \delta)$, this parameter is described as:

$\tan \delta \frac{\varepsilon^{\prime \prime} \mathrm{r}(\omega)}{\varepsilon^{\prime} \mathrm{r}(\omega)}$

Fig. 18 shows the fluctuation of the dissipation factor $(\tan \delta)$ as a function of temperature for different frequencies. At low temper ature, the variation of $\tan \delta$ is almost constant until it reaches an asymmetric loss peak at $333 \mathrm{~K}$, confirming the limited reorientation motion and then reorientation motions of these groups. At high temperature, curve rises within the whole frequency range, pre sents a wide maximum and then decreases at $363 \mathrm{~K}$. Consequently, this behavior can be explained by the interaction weakness be tween ions induced by the disorder and the reorientation move ment of the inorganic groups.

Fig. 19 presents the variations of the loss factor $\left(\varepsilon^{\prime \prime}{ }_{r}\right)$ depending to the frequency at different temperatures. As observed, $\varepsilon^{\prime \prime}{ }_{\mathrm{r}}$ is high at low frequency then it decreases with rising frequency. At low frequency region, the dielectric loss increases clearly with tem perature. Then, it indicates a dispersive behavior owing to the po larization of space charge, explained through the spreading and accumulation of the proton close to the electrode. As frequency rises, the fluctuation of the applied field becomes too fast and the dipoles will be unable to attend it. After, $\varepsilon^{\prime \prime}{ }_{\mathrm{r}}$ approaches approxi mately to values close to zero [40].

The fluctuation of the dissipation factor $(\tan \delta)$ versus frequency is depicted in Fig. 20. These plots show a similar behavior to that of the variation of the loss factors $\left(\varepsilon^{\prime \prime} r\right)$ which, decreases progressively with increasing both temperature and frequency. Such behavior confirms the presence of the dielectric relaxation phenomenon in the sample.

The dielectric study shows clearly two phase transitions observed in the title compound. The first can be assigned to a

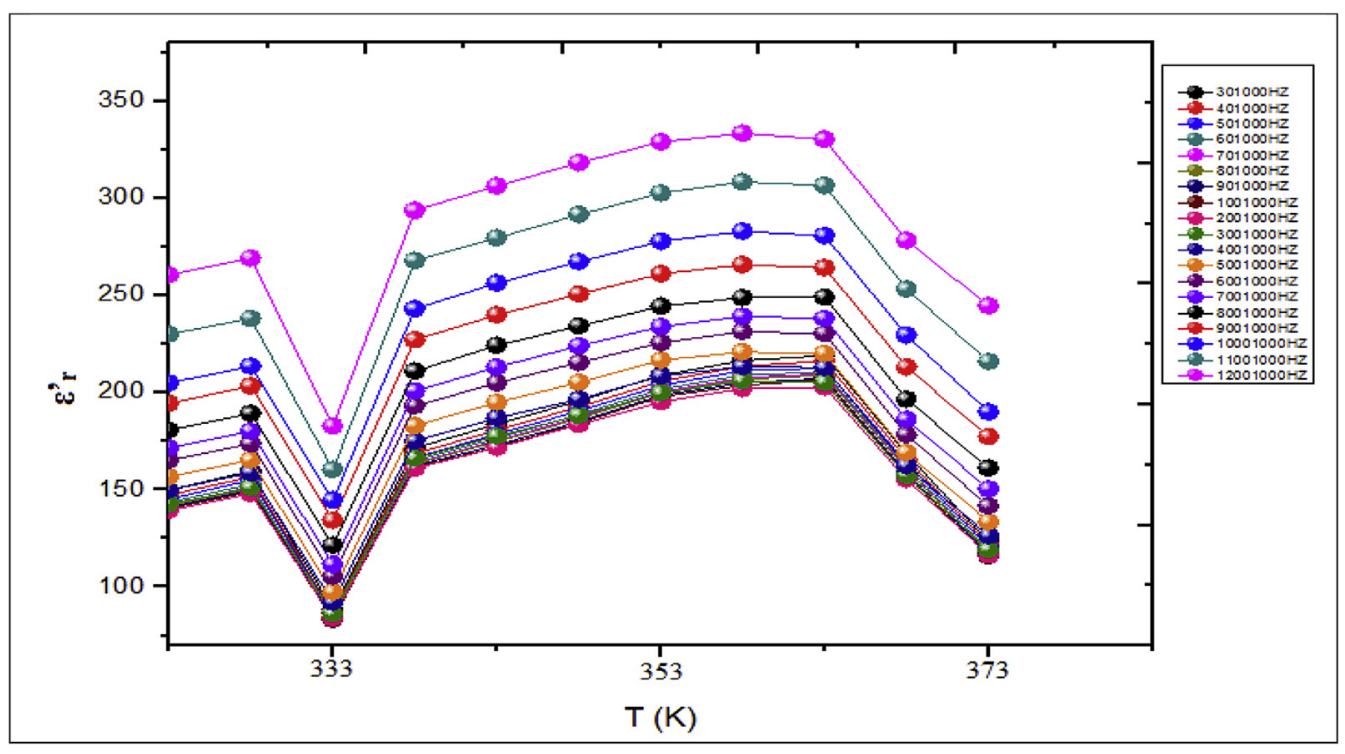

Fig. 16. Temperature dependence of the electric permittivity in TESe. 


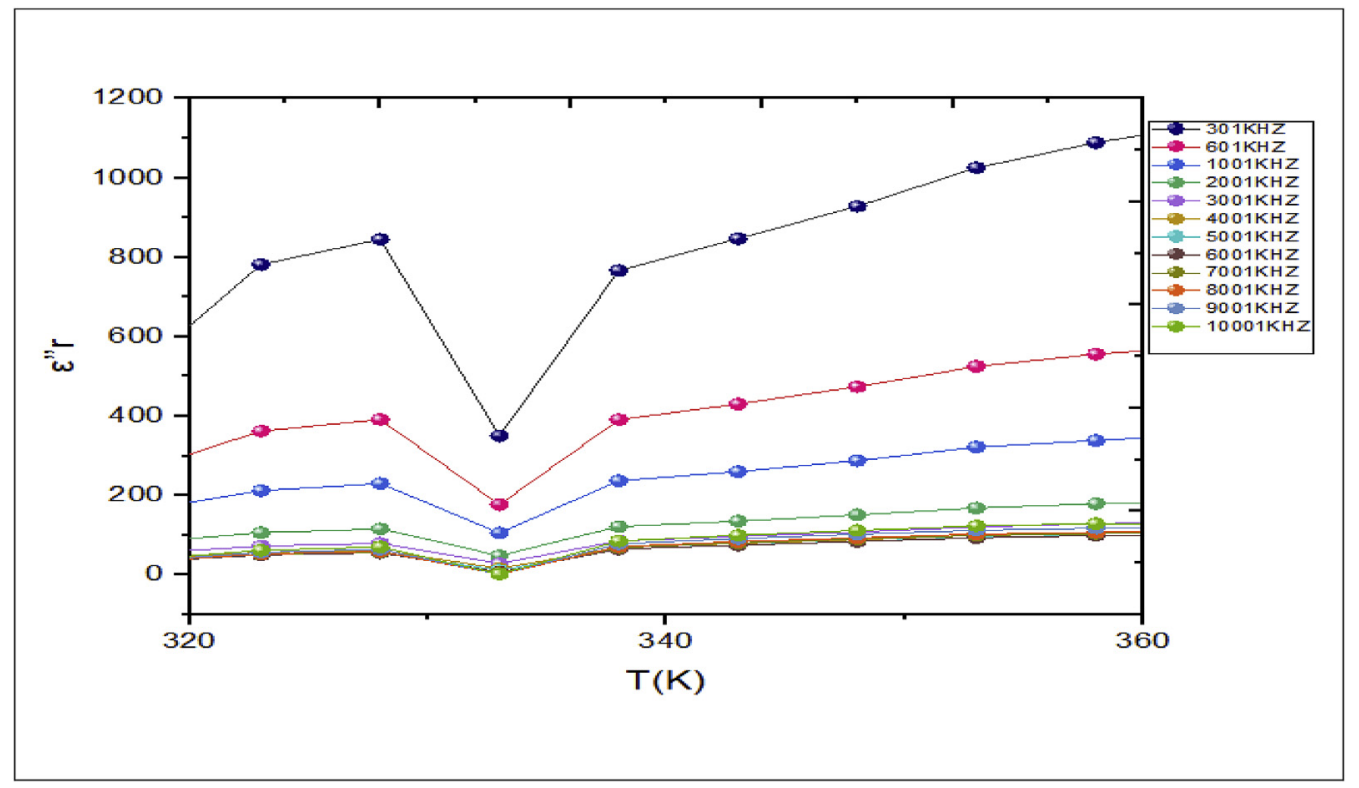

Fig. 17. Variation of the dielectric loss according to the temperature for different frequencies.

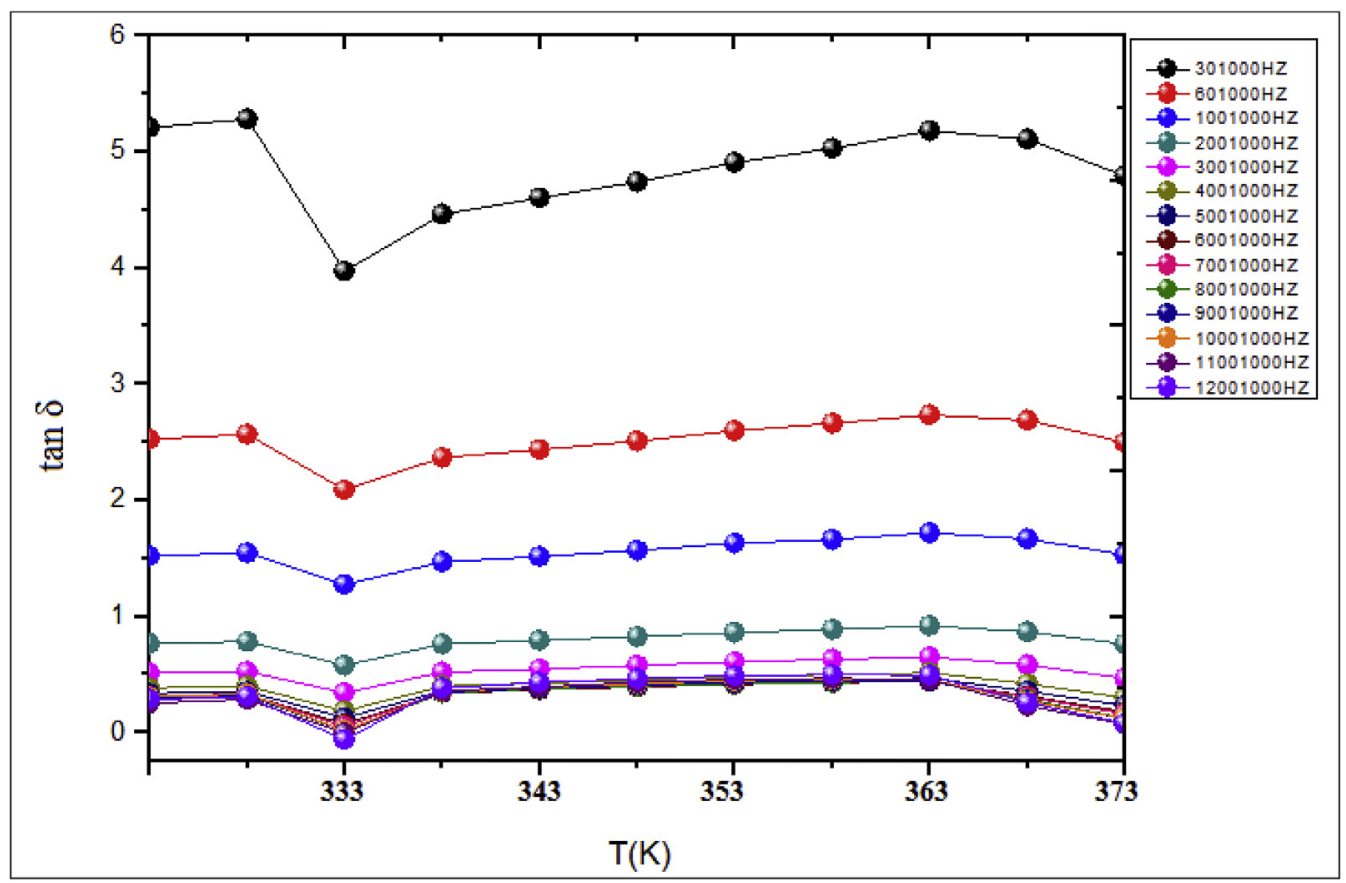

Fig. 18. Fluctuation of the dissipation factor $(\tan \delta)$ as a function of temperature for different frequencies.

disorder generated from the reorientation motion of the inorganic groups and the second may be attributed to order disorder phase transition stressed by the diffusion of the $\mathrm{H}^{+}$protons.

\subsection{Investigation of the proton conduction mechanism}

The diffusion of protons through the chemical species is described within the framework of the vehicle and Grotthuss mechanisms $[19,20]$. In the first mechanism, proton conductivity is achieved through the migration of the vehicle or proton solvent. Clearly, the vehicle diffusion rate is highly related to the overall proton conductivity. In contrast, in the Grotthuss mechanism (known also as proton jumping) proton solvent or vehicle are not necessary and proton conductivity is achieved by transfer of pro tons from one site to another via the formation and breakage of hydrogen bonds.

In the case of TESe the $\mathrm{SeO}_{4}$ tetrahedral are donor and acceptor of charges. The phase transition observed is closely related to the rotation or liberation of the anionic groups when heating. Thus, the movement of the charge carriers is closely related to the tetrahedral dynamic. The increase in $\mathrm{SeO}_{4}$ groups libration with the rise of temperature allow to lengthen short inter atomic distances, the hydrogen bonds breaking, $\mathrm{H}^{+}$protons movement and the anionic groups reorientation. Consequently, the process of charge transport follows the Grotthuss mechanism [20]. 


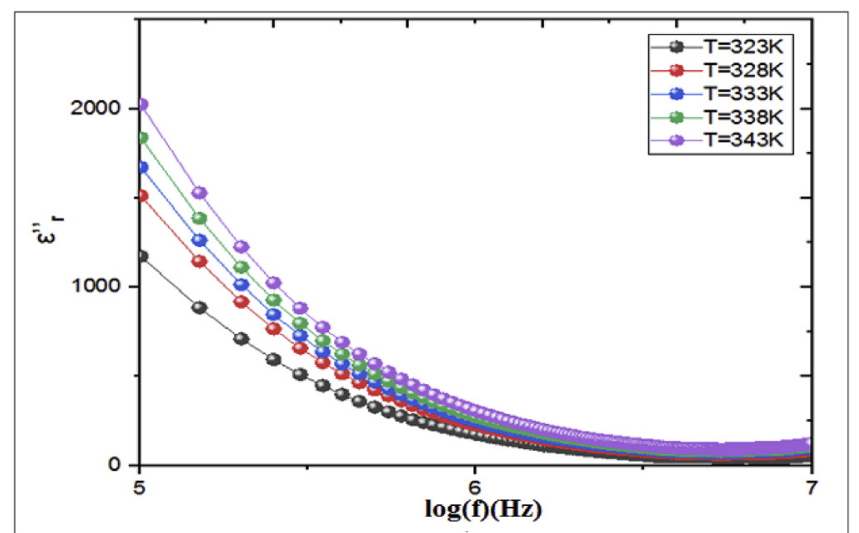

Fig. 19. The variations of the loss factor $\varepsilon^{\prime \prime}{ }_{\mathrm{r}}$ depending on the frequency at different temperatures for the title compound.

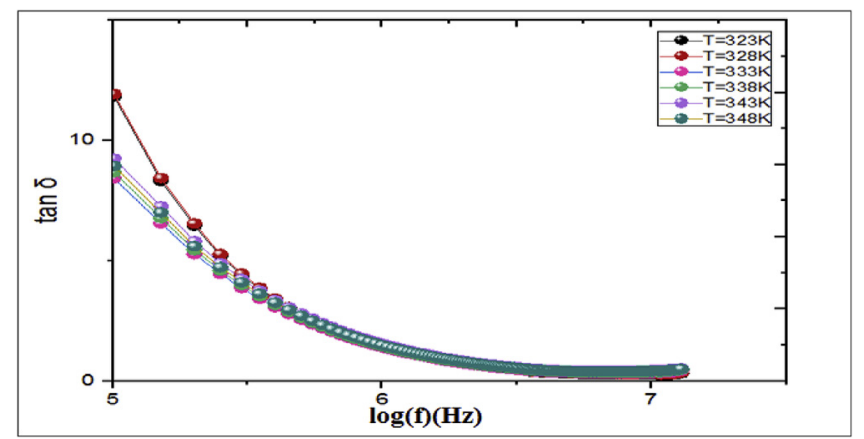

Fig. 20. Fluctuation of the dissipation factor $(\tan \delta)$ versus frequency for some temperature.

\section{Conclusion}

In summary, a novel selenate hybrid compound based on Tet raethylammonium with the general formula $\left[\left(\mathrm{C}_{2} \mathrm{H}_{5}\right)_{4} \mathrm{~N}\right] \mathrm{HSeO}_{4}$ $\left(\mathrm{H}_{2} \mathrm{SeO}_{4}\right)_{2}$ was prepared and crystallized at room temperature by the slow evaporation technique.

Crystallographic studies using Single crystal $\mathrm{X}$ ray diffraction revealed that TESe belongs to the monoclinic symmetry with the Cc space group. The asymmetric unit contains one independent $\left[\left(\mathrm{C}_{2} \mathrm{H}_{5}\right) \mathrm{N}^{+}\right]$cation, one $\left[\mathrm{HSeO}_{4}\right]^{2-}$ and two neutral selenic acid $\mathrm{H}_{2} \mathrm{SeO}_{4}$. The structure consists of a layered organization of organic and inorganic sheet along the $\mathrm{b}$ axis and the inorganic groups are interconnected through strong $\mathrm{O}-\mathrm{H} \cdots \mathrm{O}$ hydrogen bond yielding infinite 2D planes.

Thermal measurements were carried out revealing the appear ance of two phase transitions which is subsequently confirmed by the electrical and dielectric analysis. Complex impedance analyses over temperature and frequency allow us to determine the equiv alent circuit and electric measurements reveal that this material is a super protonic conductor. Dielectric analysis indicates that the title compound presents a dielectric relaxation phenomenon.

Finally, the transport process results from the jumping of $\mathrm{H}^{+}$ protons between $\mathrm{SeO}_{4}$ groups. Proton conduction can be ascribed to the transfer through hydrogen bonds and movements of charges carriers, and then it arises by the Grotthuss mechanism. Therefore, these results appear to be an interesting route to develop a new proton conducting compounds for specific applications in electro lytes and batteries.

\section{Declaration of competing InterestCOI}

The authors declare that they have no known competing financialinterestsor personal relationships that could have appeared to influence the work reported in this paper.

\section{Acknowledgements}

A great thanks for ICMCB Bordeaux France, specially the XR diffraction service and all the members of the group Molecule and switchable materials.

\section{Appendix A. Supplementary data}

Supplementary data to this article can be found online at https://doi.org/10.1016/j.jallcom.2020.153826.

\section{References}

[1] D. Hoel, E. Grunwald, J. Phys. Chem. 81 (1977) 2135.

[2] H. Steininger, M. Schuster, K.D. Kreuer, A. Kaltbeitzel, B. Bingol, W.H. Meyer, S. Schauff, G. Brunklaus, J. Maier, H.W. Spiess, Phys. Chem. Chem. Phys. 9 (2007) 1764

[3] K.D. Kreuer, Chem. Mater. 8 (1996) 610.

[4] K.D. Kreuer, S.J. Paddison, E. Spohr, M. Schuster, Chem. Rev. 104 (2004) 4637.

[5] C. Sanchez, F. Ribot, New J. Chem. 18 (1994) 10071074.

[6] S. Hajlaoui, I. Chaabane, A. Oueslati, K. Guidara, A. Bulou, Spectrochim. Acta, Part A 117 (2014) 225233.

[7] M. Ben Bechir, K. Karoui, M. Tabellout, K. Guidara, A. Ben Rhaiem, J.Alloys.Compd. 588 (2014) 551557.

[8] V. Kapustianyk, J. Phys. Stud. 17 (2013) 17021724.

[9] F. Arrakhiz, Z.K. Benmoussa, R. Bouhfid, A. Qaiss. Mater. Des. 50 (2013) 376381.

[10] H. Yu, X. Zhang, Z. Shi, K. Alimaje, Y. Shen, J. Pen, B. Li, L. Zhang, Dyes Pigments 98 (2013) 479485.

[11] M.K. Marchewka, J. Janczak, S. Debrus, J. Baran, H. Ratajczak, Solid State Sci. 5 (2003) 643652.

[12] W. Maalej, A. BenRached, T. Mhiri, A. Daoud, N. Zouari, Z. Elaoud, Phys. Chem. Solids 96 (2016) 9299.

[13] M. Drozd, J. Baran, A. Pietraszko, Spectrochim. Acta (2005) 27752787

[14] M. Fleck, Acta Crystallogr. E62 (2006) 49394941.

[15] M. Drozd, J. Baran, Spectrochim. Acta PartA 61 (2005) 29532965.

[16] B. Hilczer, M. Polomska, A. Pawlowski, Solid State Ion. 125 (1999) 163169.

[17] A. Pawlowski, B. Hilczer, M. Polomska, A. Pietraszko, Solid State Ion. 145 (2001) 217224

[18] J. Baran, M. Sledz, M. Drozd, A. Pietraszko, A. Haznar, H. Ratajczak, J. Mol. Struct. 526 (2000) 361371.

[19] J. Baran, T. Lis, Acta Crystallogr. 42 (1986) 270.

[20] J.P. Ashmore, H.E. Petch, Can. J. Phys. 53 (1975) 2694.

[21] L.J. Farrugia, J. Appl. Crystallogr. 32 (1999) 837.

[22] G.M. Sheldrick, SHELXS-86, Program for the Solution of CrystalStructure, Univ. of Gottingen, Germany, 1990

[23] G.M. Sheldrick, Acta Crystallogr. E 64 (2008) 112.

[24] K. Brandenburg, Diamond Version 2.0, Impact GbR, Bonn, Germany, 1998

[25] I. Dhouib, P. Guionneau, T. Mhiri, Z. Elaoud, Eur. J. Chem. 3 (2014) 388394.

[26] M. Nefzi H, F. Sediri, H. Hamzaoui, N. Gharbi, Mater. Res. Bull. 48 (2013) 1978.

[27] N.L. Nkhili, W. Rekik, H. Naïli, T. Mhiri, T. Bataille, Arab. J. Chem. 10 (2017) S2509 S2517.

[28] M. Abbassia, R. Ternane, I. Sobrados, A. Madani, M. Trabelsi-Ayadi, J. Sanz, Ceram. Int. 39 (2013) 9215.

[29] P.C. Sati, M. Arora, S. Chauhan, M. Kumar, S. Chhoker, Ceram. Int. 40 (2010) 43.

[30] M. Ram, Solid State Sci. 12 (2014) 350.

[31] S. Kulkarni, B.M. Nagabhushana, N. Parvatikar, A. Koppalkar, C. Shivakumara, R. Damle, Mater. Res. Bull. 50 (2014) 197202.

[32] F.S. Howell, R.A. Bose, P.B. Maado, C.T. Modynihan, J. Phys. Chem. 78 (1974) 639.

[33] F. Alvarez, A. Alegría, Interconnection between Frequency-Domain Havriliak Negami.

[34] L. Pengfei, L. Yanyan, L. Fuchao,C. Xiaolian, Y. Zupei, Mater. Res. Bull..

[35] C.T. Moynihan, L.P. Boesch, N.L. Laberge, Phys. Chem. Glasses 14 (1973) 122125.

[36] K. Srivastava, A. Kumar, O.S. Panwar, L.N. Lakshminarayan, J. Non-Cryst. Solids (1979) 33205.

[37] A. Piecha, A. Gagor, M. Weclawik, R. Jakubas, W. Medycki, Mater. Res. Bull. 48 (2013) 151157

[38] ShA. Mansour, I.S. Yahia, F. Yakuphanoglu, Dyes Pigments 87 (2010) 144148.

[39] S. Hajlaoui, I. Chaabane, A. Oueslati, K. Guidara, Solid State Sci. 25 (2013) 134142.

[40] H. Belgaroui, M. Loukil, A. Kabadou, H. Khemakhem, A. Ben Salah, J. Chem. Crystallogr. 43 (2013) 352359. 